\title{
Does Case Study Research Strategy Get Along With The Information System (IS)?
}

* M. M. Shankar

\begin{abstract}
Does case study research strategy get along with the Information System (IS)? The primary objective of this paper is to answer this question and also bring about awareness on Case Study research strategy which includes challenges, initial developments, current practices, trend and limitations, and key contributors. This paper contributes in providing awareness among researchers especially in Information System domain and also providing fundamental understanding on role of Case Study research usage for nearly two decades in Information System.
\end{abstract}

\section{Introduction}

Case Study research: Most of our researchers embraced survey research strategy, the awareness about Case Study research strategy is less. The objective of this paper is to understand the challenges and how they could be overcome through the developments of Case Study as a research strategy in the field of Information System (IS). There are numerous research strategies available in research: Survey, Experimental, Field study, etc. Every research strategy has its own positive and negative influences in the eyes of researchers. This paper focused on Case study research, is the second most attractive research strategy in IS (Chen \& Hirschheim, 2004). However, the interest and awareness about Case Study research is less among the researchers in the field of IS. This is well understood from the fact that only $9.1 \%$ of the researchers used Case Study methodology in between 19681988 (Alavi et al., 1992) and on the other hand, it is also equally surprising to note that Field Studies are the most attracted and used research methodology by $33.4 \%$ of the researchers. Keeping all this in view, this paper has attempted to elaborate the development of Case Study as a mode of Research and also creating awareness among the research scholars on Case Study in the field of IS. The following sections describes the challenges and how they could be overcome, initial developments, current practices, trend and issues, and the last section highlights the key contributors of Case Study research in IS.

* Assistant Manager - Research \& Analytics, Satyam BPO Ltd., Bangalore, Mobile : 9901857466

Email : mmshankar@gmail.com 


\section{Challenge against Case Study research}

There were lot of controversies and arguments on Case Study research as a research design. The key points that were initially discussed are given below:

- There is confusion between Case Study research method and Case Study teaching method. But there are differences. (Refer Annexure 1.)

- Miles (1979) raised lot of queries about qualitative research and primarily stated that Case Study analysis was essentially intuitive, primitive \& unmanageable.

- Generalizing the results in terms of statistical and theoretical concepts was still questionable for most of the researchers, which also in fact includes Case Study research (Lee \& Baskerville, 2003).

- Is Case study purely qualitative?

- Whether Case study can be used for exploring theory?

\subsection{Case Study Research as Scientific Method}

Robert K Yin (Yin, 1981) answered the queries raised by Miles (1979) to reaffirm the role of the Case Study as a systematic research. Yin (1982) highlighted some of the challenges of Case Study research especially in crafting social sciences research intertwined with phenomenoncontext, fixing relevant unit of analysis, and collection of data, et cetera.

\subsection{Concept of Generalizability in Case Study research Strategy}

In spite of Case Study research gaining enormous support and usage by research scholars, there were arguments regarding the credibility of the use of a single Case Study for the purpose of generalizability and to make controlled deductions. For instance, good number of authors are concerned about generalization of one Case Study outcome to the whole population of the given study. Their quotations are given below

- "To what extent can the findings from this study generalize to other organizations and their practice" (Tyran et al., 1992).

- "We must not generalize from a single case study in one organization" (Vadenbosch and Ginzsberg, 1996).

- "Because they are drawn from a study of two organizations, these results should not generalize to other contexts" (Robey and Sahay, 1996).
- In particular, in-depth analysis of extensive data from only one organization reduces generalizability, but increases correspondence to reality" (Hirschheim et al., 1998).

- "There are of course, many methodological limitation of this study. As a small sample-size, single case study, generalizability cannot be assessed" (Majchrzak et al., 2000).

From the perspectives by different scholars, it is clearly understood that even among the scholars there is hesitant generalization to give the result of one Case Study to the whole population. But, however, Lee and Baskerville (2004) clarified the above controversies and arguments that majority of the published researchers opted for the Statistical and Sampling based concept of generalizability such as Case Study to Non-Statistical and Non-Sampling research.

Yin $(1984 ; 1994)$ also contributed to the concept of generalization which described the Level-1 inference as Statistical generalizability and Level- 2 inference as Case Study research methodology to theory. Most of the IS researchers were generally found to be using Level-1 inference as Case Study for generalizability which was highlighted as the misapplication of the concept of statistical generalizability in IS besides this, Yin (1984; 1994) also contributed to the framework for classification of four types of generalizing and generalizability, which was beyond the sampling based research. Lee (1989) also suggested methodologies and systemized solutions for the use of Case Study research in the field of is to overcome the problem of generalization.

\subsection{Case Study - Combination of both Qualitative and Quantitative.}

In the field of IS, there is always an ongoing debate as to whether qualitative methods or quantitative methods could be used. It was found that there was a better support for quantitative methods rather than qualitative methods. To overcome this, Kaplan and Duchon (1988) figured suggestions for the combined use of qualitative and quantitative methods through Case Studies in the field of IS. 


\subsection{Case Study research aided for Building Theory}

Until 1989, case studies were used as tools to test existing theories and concepts. But a significant transformation occurred in 1989 when Kathleen $M$ Eisenhardt (1989) demonstrated that theories could also be built based on case studies. Interesting contributions made by Eisenhardt (1989) can be discussed from two different perspectives. Firstly, case studies could be used as road maps for constructing and building theories and secondly, case studies could also be used as source in theory building in the larger context of social science research.

\section{Initial Developments of Case Study research in IS}

One of the early and most remarkable empirical research based on case studies was contributed by $M$. Lynne Markus (1983) based on theory of people, system, and interaction. Till recently this work has been appreciated as an exemplary work in a special article in journal MISQ (2004). However, this contribution lacked to incorporate broad Case Study research guidelines provided by Yin (1982). In 1984, Yin provided great insights and broad guidelines for the researchers who were interested in using case study methodology as a research design and thereafter published a book on Case Study research Design.

Before Yin (1982) there were only generic guidelines available for case study research which was contributed by research scholars. Significant and note worthy contributions by Benbasat et al. (1987) in the field of case study research Methodology in IS paved way for a significant growth. Their combined efforts and work played a vital role in providing broad guidelines and characteristics of case study research in IS. Few Case Studies were also narrated by Benbasat et al. (1987) to supplement the concepts and support the characteristics specified by Yin (1984).

\section{Current Practices, Trends and Issues in Case Study research}

There are indeed enormous contributions in the use of Case Study as a methodology in research. Contributions by Blonk (2003) added new perspectives and new dimensions in this area by highlighting the use of methodological dimensions in writing case studies in IS Research. The typology is basically based on $2 \times 2$ matrices, resulting in four forms of writing case studies: Chronology, Play, Biography and Voices.

Chen and Hirschhein (2004), in his paradigmatic and methodological examination of IS research examined 1983 articles published in 8 major IS publication outlets between 1991 and 2001. It was found that Positivist dominated $81 \%$ of the published empirical research and the rest were Interpretisitivism and Critical Research philosophy. Dube and Pare (2003) also extended this to case study research design where most of the researchers used Positivist philosophy rather than Interpretisitivism. Dube and Pare (2003) clearly depicted the levels and amount of rigor reflected in is Positivist Case Study research. Besides this, they also highlighted the statistical figure details of the case study research design followed over a decade.

There were indeed lot of contributions to the broad and macro perspective of Case Study research in IS, which of course helped researchers to gain a holistic view of case study research. Remarkable contributions by Guy Pare (2004) reflected the micro perspective of case study research; a step-by-step methodology together with a set of key concepts, techniques, and tools on how to conduct quality positivist case research. However, the study confined to exploratory (theory building) case study research rather than explanatory (theory testing). Keil (1995) and Pare and Elam (1997) added upon to his finding, illustrating the use of Single and Multi-Case Study designs respectively. Case study research was not only restricted to Positivist philosophy but was also extended to Interpretivist research philosophy. Walsham (1995) also demonstrated the interpretive approach to doing case study research. He addressed the philosophical and theoretical issues based on Interpretative case studies and also their methodological issues. 
Chen and Hirschheim (2004) found that most of the researchers used quantitative oriented research design like survey design as they were less time consuming, especially positivism, and also, because the researchers were subject to continuous pressure in their workplace for tenure and promotion, based on the quantity of publications. However, this trend underwent a change after Allen Lee took over as 'Editor-in-Chief' of Journal of Management Information System Quarterly. Palvia et al. (2003) found that most of the articles published in the "Application" section of MISQ were case studies. Chen and Hirschheim (2004) also found that there was a remarkable and paradigm shift in research designs; $46 \%$ Survey design and $34 \%$ case studies, between the years 1991-2001. Besides this, case study researchers were finding immense publication opportunities in the Journals such as Information and Organization, Journal of Information Technology and Information System of Journal and European Journal of Information System. Journal of Information Technology Cases \& Applications is a new Journal on case study research. It was also found that in 1993, case study research occupied sixth position in the research designs among research methods and subsequently, during 1997, it was found to be the most preferred methodology among research scholars Palvia et al. (2003). The quality and quantity of case study researches are increasing when compared to two decades back, especially before 1987 . This is solely due to the remarkable changes happening in IS which is enriching the domain. At the same time, the weaknesses imbibed in the case study research design is also gradually getting reduced by lot of remarkable contributors in case study research in the field of IS.
It is understood that there are lot of great insights and remarkable contributions in the mode of case study research as a design among the researchers in the IS field. But it is equally heartening to note that there are not many publications pertaining to this area. Avison and Heje (2006) also found that many of the reputed and leading IS Journals encouraged quantitative based research design such as survey methods and owing to page restriction practices, limited the researchers in case studies publications. Added to this, another strong reason felt was that there were no standard formats to publish a case study research like a survey design.

However, this issue was addressed in the 8th Australian Conference on Information Systems held in 1997. Darket et al. (1998) outlined the outcome of the panel session conducted by them. It addressed the frequently asked questions while choosing and conducting Case Study research in IS pertaining to designing participation of organization, data collection and establishment of rigor to publish Case Study research in academics journals.

\section{Key Contributors to Case Study research in is}

Case study as a research methodology was largely a source of inspiration by the work of Yin (1984; 1994; 2003). Benbasat et al. (1987), Eisenhardt (1989), Lee (1989) and Dube and Pare (2003) in fact, really shaped the positivist case study research, especially in IS domain. In the field of intrepretivist, Walsham (1994; 1995), Miles and Huberman (1994) offered practical guidelines in the form of a book for qualitative data analysis which includes case study research.

In recent times, Case Study research greatly established its role in the domain of Information Systems, which enriched the domain by way of exploring and explaining theory. Hence, as a researcher, one can also utilize Case Study research strategy as one of the options in future researches in any management discipline which includes IS. 
Annexure 1

A Case Study Teaching as contrasted to a Case Study research

\begin{tabular}{|c|l|l|l|}
\hline $\begin{array}{c}\text { S1. } \\
\text { No. }\end{array}$ & Element & \multicolumn{1}{|c|}{ Case Study Teaching Method } & Case Study Research Method \\
\hline 1. & Purpose & $\begin{array}{l}\text { Produced primarily for teaching and } \\
\text { training purpose. Not intended to generate } \\
\text { new theories, just to illustrate an abstract } \\
\text { argument and help students develop a } \\
\text { general insight into real life situations. }\end{array}$ & $\begin{array}{l}\text { To facilitate new insights into current } \\
\text { knowledge and theory in the filed. To } \\
\text { explore unknown areas and refine } \\
\text { concepts in order to build or test a theory. }\end{array}$ \\
\hline 2. & Nature & $\begin{array}{l}\text { Events in the near past are preferred. The } \\
\text { case may be fictious, although real life } \\
\text { cases are preferred. }\end{array}$ & $\begin{array}{l}\text { Concurrent evens are preferred. The case } \\
\text { must be real. }\end{array}$ \\
\hline 3. & $\begin{array}{l}\text { Data } \\
\text { Collection }\end{array}$ & $\begin{array}{l}\text { The emphasis is on obtaining the "whole } \\
\text { story" and not on "how". }\end{array}$ & $\begin{array}{l}\text { The methodology is a crucial consideration. } \\
\text { A case study is only as good as its } \\
\text { methodology of research. }\end{array}$ \\
\hline 5. & Content & $\begin{array}{l}\text { A case is described to the end, and infor- } \\
\text { mation is provided on: (1) the event, (2) its } \\
\text { background, and (3) its conclusion. }\end{array}$ & $\begin{array}{l}\text { A case is described in full. In addition, } \\
\text { analysis of the data together with the } \\
\text { author's conclusion is included. }\end{array}$ \\
\hline Length & $\begin{array}{l}\text { Lengthy case is cumbersome and often } \\
\text { unmanageable for class use. A case which } \\
\text { may run to fifty pages is often considered } \\
\text { too lengthy. }\end{array}$ & $\begin{array}{l}\text { Length is not an important consideration. } \\
\text { The important thing is to get all the data, } \\
\text { analysis and discussion into the Study. } \\
\text { A case study reported in more than 1000 } \\
\text { pages is not too long. }\end{array}$ \\
\hline
\end{tabular}

Source: Jain, Sagar, Laurel F. Gooch and Emily V. Granthan.

\section{REFERENCES}

1. Robert K. Yin (1981), Case Study Crisis: Some Answers, Administrator Service Quality, March (Vol. 26).

2. Robert K. Yin (1982), Studying Phenomenon and Context Across Sites. The American Behovorial, $26,1$.

3. M. Lynne Markus (1983), Power, Politics and MIS Implementation. Communication of the ACM, Vol. 26, 6.

4. Benbasat, Goldstein, Mead (1987), The Case Research Strategy Studies in IS. MIS Quarterly, September.

5. Kaplan, Duchon (1988), Combining Qualitative and Quantitative Methods in IS Research Case Study, MIS Quarterly.

6. Allen S. Lee (1989), A Scientific Methodology for MIS Case Studies, MIS Quarterly, March.

7. Kathleen M. Eisenhardt (1989), Building Theories from Case Study research, Academy of Management Review, Vol. 14, No. 4.

8. Orlikowski and Baroudi (1991), Studying Information Technology in organizations: Research Approaches and Assumptions, Information Systems Research, Vol. 2, No. 1.

9. Alavi, Maryam, Carlson and Patricia (1992), A review of MIS research and disciplinary development, Journal of MIS, Vol. 8, No. 4. 
10. Pete Darket, Graeme Shanks and Marianne Broadbent (1998), Successfully completing Case Study research: combining rigor, relevance and pragmatism, Info Systems Journal, Vol. 8.

11. Allen S. Lee and Richard L. Baskerville (2003), Generalizing Generalizability in Information Systems Research, Information Systems Research, Vol. 14, No. 3.

12. Heico Van Der Blonk (2003), Writing Case Studies in Information Systems Research, Journal of IT, Vol. 18.

13. Dube and Pare (2003), Rigor in IS Positivist Case Research: Current Practices, Trends, and Recommendations, MIS Quarterly, Vol. 27, No. 4.

14. Chen and Hirschheim (2004), A paradigmatic and methodological examination of information systems research, Info Systems Journal, Vol. 14.

15. Guy Pare (2004), Investigating Information Systems with Positivist Case Study research, Communication of the Association for Information System, Vol. 13.

16. Palvia, E. Mao, A.F. Salam and K.S. Soliman (2003), Management Information Systems Research: What's there in a Methodology?, Communication of the Association for Information Systems, Vol. 11.

17. David Avison and Jan Pries-Heje (2006), A handbook for research supervisors and their students.

18. Majchrzak, Rice, A. Malhotra, N. King and B. Sulin (2000) “Technology adaptation: The case of computer-supported interorganizational virtual team", MIS Quarterly, Vol. 24, No. 4.

19. Vandenbosch, Ginzsberg (1996) "Lotus notes and collaboration: plus change”, Journal of MIS, Vol. 13, No.3.

20. D. Robey, S. Sahay (1996), "A comparative case study of GIS in country government", Information Systems Research, Vol. 7, No. 1.

21. R. Hirschheim, M. Newman, J. Degross (1998), "Adoption of IS development methods across cultural boundaries", Int. Conf. IS.

22. Tyran.C, A. Dennis and D. Vogel (1992), "The application of electronic meeting technology to support", MIS Quarterly, Vol. 16, No. 3.

22. Jain Sagar, Laurel F. Gooch and Emily V. Grantham (1975), "Case writing do's and don'ts, Chapel Hill University of North Carolina. 